\title{
A mathematical model of odor dispersion from a wastewater treatment plant
}

\author{
Valerii Azarov*, Tat'yana Solov'eva, Sergei Svitskov \\ Volgograd State Technical University (VSTU), 400074, Volgograd, Russian Federation
}

\begin{abstract}
Smell is an important criterion of the quality of atmospheric air. The paper looks at quantitative and qualitative methods of odor assessment and describes the method of field olfactometry. Studies were carried out on the spread of odor from the WWTP OAO OKOS in the Kaliningrad region of Russia which resulted in 817 measurements. For each measurement, the following parameters were recorded: odor strength $(\mathrm{D} / \mathrm{T})$, odor character, atmospheric pressure $(\mathrm{mmHg})$, temperature $\left({ }^{\circ} \mathrm{C}\right)$, relative humidity $(\%)$, wind speed $(\mathrm{m} / \mathrm{s})$, wind direction and the the point where a measurement was taken. A mathematical model is given of the dependence of odor strength on the distance to two sources $\mathrm{s} 1 \mathrm{(m})$ and $\mathrm{s} 2(\mathrm{~m})$ and the wind direction from a straight line passing through a given point and a source 1 - a1 or a source $2-\mathrm{a} 2$.
\end{abstract}

\section{Introduction}

The choice of a particular schedule of experimental data collection is defined by the aims of the research, the accuracy requirements of the measurements, the distinctive features of a facility, the facility's location, the odor source type, the characteristics of the surrounding area and the technical possibilities for carrying out measurements. Moreover, as odor perception is influenced by such factors as the assessor's individual subjective features and the weather conditions, it is important to set up a monitoring schedule such that the research period covers different seasons (especially the warm period) and measurements are carried out by different assessors at different times of the day and in different meteorological conditions (temperature, relative humidity, barometric pressure, wind speed and wind direction) in order to minimize the influence of the mentioned factors on the final result.

The choice of measurement points is mainly defined by the aims of the research. As odor is an environmental factor that has a direct impact on humans, field odor studies are usually carried out in close proximity to places where people are present: for example, in the area of a facility to evaluate working conditions or at the boundary of a sanitary protection zone [Note: in Russia a sanitary protection zone is a special buffer zone established around facilities that affect the environment and people's health.], and in residential areas to assess the life quality of people in general. The disposition of the points in a residential area can also vary: for example, if the facility is situated in a densely built-

\footnotetext{
*Corresponding author:ptb2006@mail.ru
} 
up area, the most reasonable option is to choose monitoring points at equal distances from the facility and from each other; otherwise, it is advisable to carry out odor monitoring in areas where complaints come from and where most people live and work.

\section{Methodology}

Measurements carried out sequentially in each of the chosen points make up a series. For each measurement series the following meteorological parameters are recorded in odor monitoring data sheets: relative humidity, precipitation, barometric pressure, wind speed and the prevailing wind direction. An example of an odor monitoring data sheet is presented in Figure 1.

\section{ODOR MONITORING DATA SHEET}

DATE:

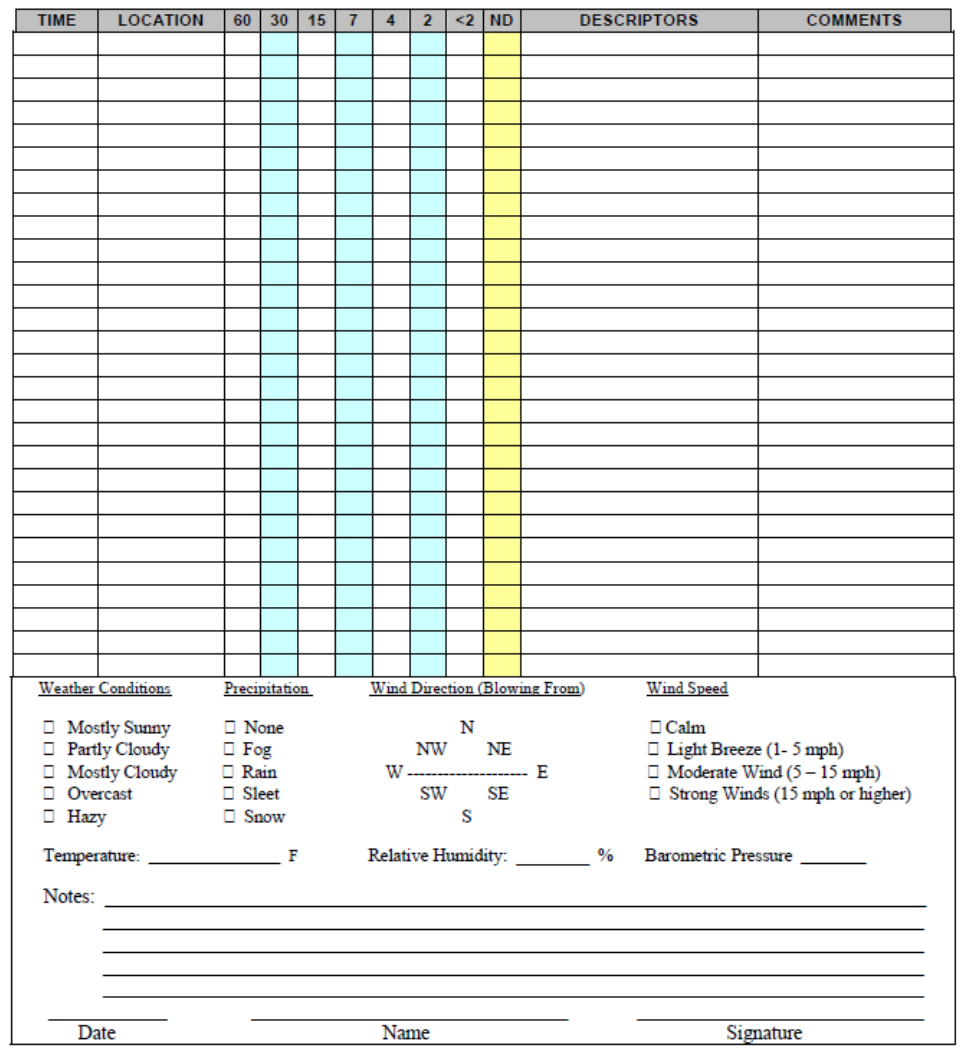

Fig. 1. Odor monitoring data sheet.

To determine the relation between the odor in the sanitary protection zone and the weather factors, monitoring points are chosen along the zone. Odor strength is measured with the help of a field olfactometer, and meteorological parameters are recorded by a portable weather station. The more accurate and objective the data must be, the more measurements it is recommended to carry out.

In field olfactometry, which is used to measure odor strength in the ambient air, odor strength is defined with the Dilution-to-Threshold ratio. This ratio is calculated by the following formula [5]: 


$$
D / T=\frac{\text { volume of carbon-filtered air }}{\text { volume of odorous air }}
$$

A device called a field olfactometer is used in such measurements. The general appearance of the Nasal Ranger field olfactometer is presented in Figure 2.

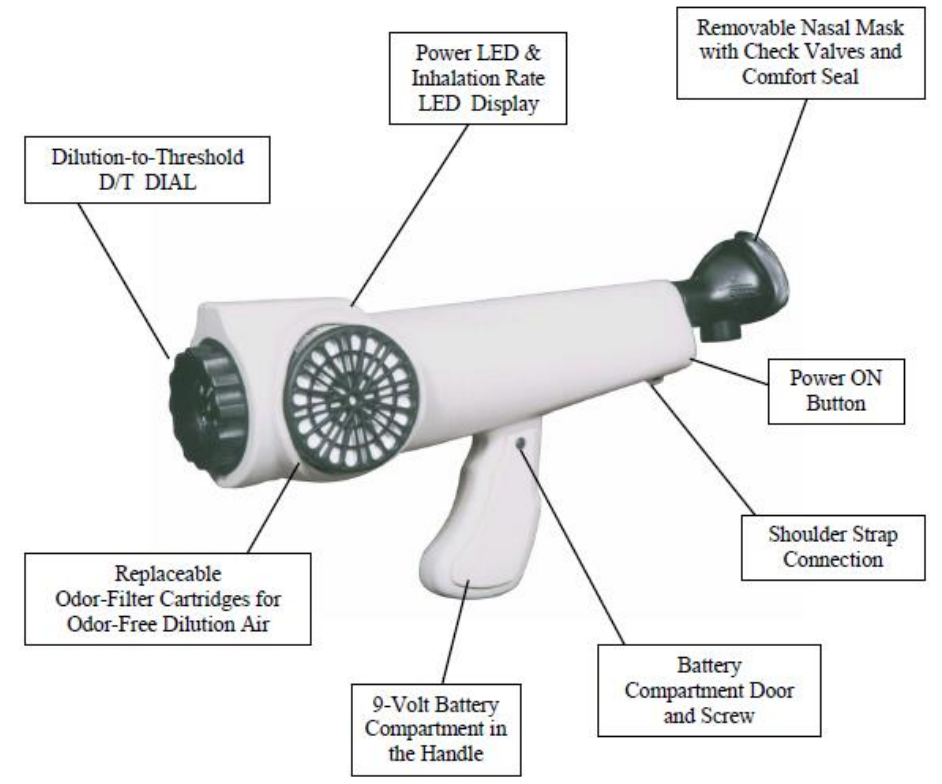

Fig. 2. Field olfactometer

The field olfactometer works by mixing odorous ambient air with odor-free filtered air in discrete volume ratios, using two airflow paths: the flow through the odor-filter cartridge, and the flow through one of the orifices in the D/T dial.

In the case of the first airflow path, ambient air, which may be odorous, enters through the outside of both odor-filter cartridges. The diameter of the orifice for the filtered air entering the device stays constant during all the measurements, and the assessor regulates his or her inhalation rate so that it lies within the required range. Thus, the incoming filtered air flow rate does not vary significantly.

In the case of the second airflow path, odorous air comes through one of the orifices on the $\mathrm{D} / \mathrm{T}$ dial. The rotational position of the $\mathrm{D} / \mathrm{T}$ dial determines the orifice size and, therefore, the volume of the odorous air that enters through the selected orifice. The larger the diameter of the selected orifice, the larger the volume of odorous air entering the olfactometer.

The two flows enter the olfactometer simultaneously, mix there and then travel to the assessor's nose, who is to determine whether the odor can be perceived. The assessor carries out a series of measurements from higher to lower dilutions, strictly following the set algorithm. The assessor registers the (maximum) $\mathrm{D} / \mathrm{T}$ value at which he or she first sensed the odor.

Thus, the Dilution-to-Threshold ratio is a measure of the number of dilutions needed to make the odorous ambient air non-detectable. As, in practice, measurements are taken from higher to lower dilutions, it can be said that the $\mathrm{D} / \mathrm{T}$ point corresponds to an odor concentration at which the assessor detects that the air is "no longer the same as it was before" [4]. 
In the study described, a Nasal Ranger field olfactometer with a 2 to $60 \mathrm{D} / \mathrm{T}$ dial was used.

A long-term study of odor dispersion from the wastewater treatment plant OAO OKOS in the Kaliningrad region of Russia was carried out. Certified assessors [6] made 43 measurement series during the spring and summer of 2017. Measurements were performed at different times of the day. The assessors took their turns in a random order.

11 points were chosen for measurements. The arrangement of the points is presented in Figure 3. Two points were located in close proximity to the malodor sources: at the wastewater inlet chamber (source 1) and near the sludge lagoons (source 2) correspondingly. All other points were situated on the road near the wastewater treatment plant at equal distances (about 200 meters) from each other, as there were no other objects nearby where people live and work. All the other nearby areas were of no practical interest for the research; thus, measurements were not taken there.

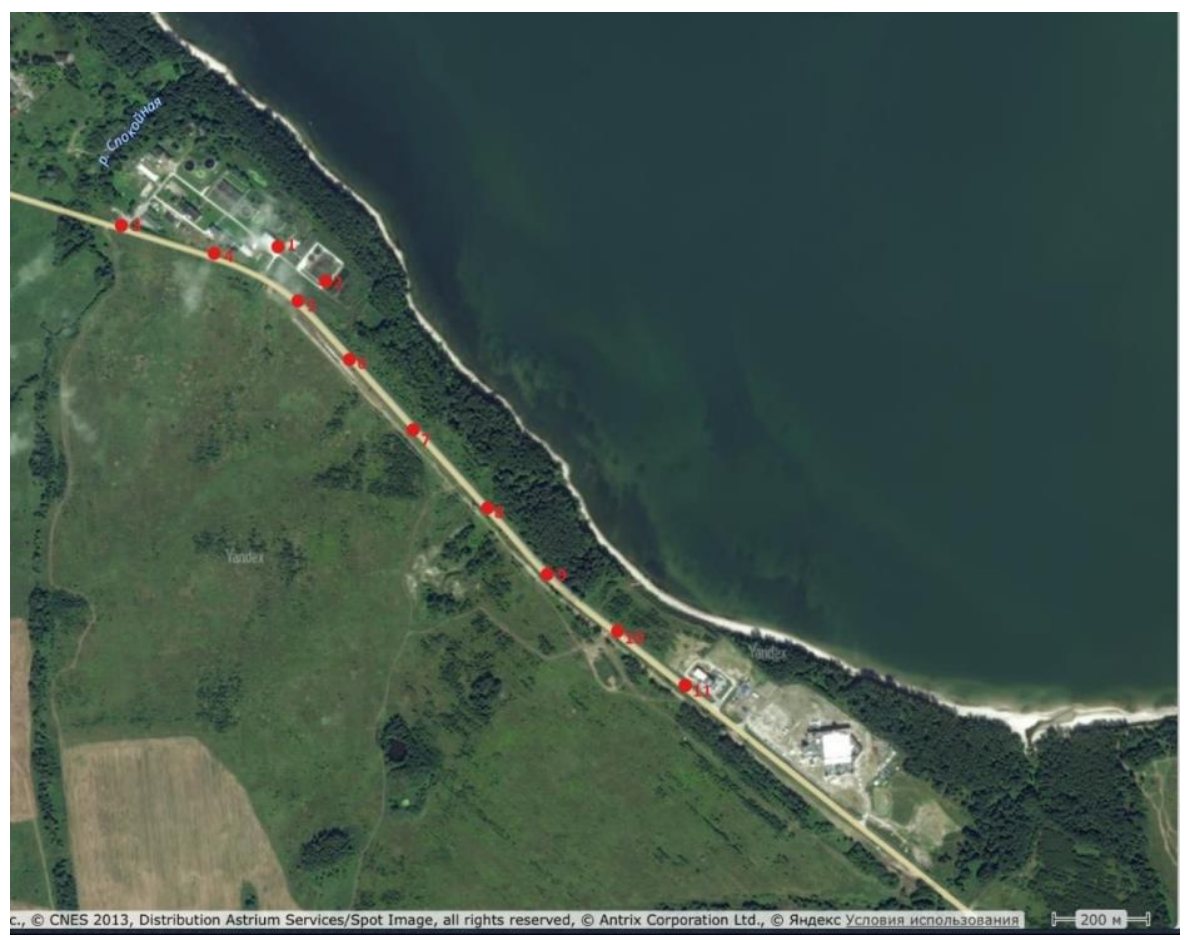

Fig. 3. The arrangement of the measurements points.

The following parameters were recorded for each measurement: odor strength $(D / T)$, odor character, barometric pressure $(\mathrm{mm} \mathrm{Hg})$, temperature $\left({ }^{\circ} \mathrm{C}\right)$, relative humidity $(\%)$, wind speed $(\mathrm{m} / \mathrm{s})$, wind direction, the measurement's point number. Later, all the types of odors recorded were divided into two groups: those connected to the operating wastewater treatment plant, and those whose occurrence can under no circumstances be attributed to the primary activity of the facility in question. The latter were excluded from further analysis. If and only if the odor character corresponded to the odor from a wastewater treatment plant, the results of the odor strength measurements were used to determine the relation between the odor strength and parameters that define the location of the points in relation to the odor sources and meteorological parameters.

An analysis was made of the relation between odor strength $I(\mathrm{D} / \mathrm{T})$ and the distances from the two sources $l_{1}(\mathrm{~m})$ and $l_{2}(\mathrm{~m})$ and the wind direction in relation to a straight line passing through the given point and source $1-a_{1}$ or source $2-a_{2}$. 


\section{Results}

A data sample of size 817 was obtained, i.e. 817 measurements were taken. The whole sample was divided into 4 groups, depending on the sign of the angle of deviation of the wind direction from a straight line passing through the given point and source $1, a_{1}$ and the given point and source $2, a_{2}$. The first group comprised the basic data corresponding to angle values $a_{1}<0, a_{2}<0$; the second group - to angle values $a_{1}>0, a_{2}<0$; the third group - to angle values $a_{1}<0, a_{2}>0$; the fourth group - to angle values $a_{1}>0, a_{2}>0$. For the first three groups the odor strength was 0 . Thus, statistical analysis was done for the data from the fourth group. STATISTICA 6.1 analytical system and EXCEL spreadsheet were used for the analysis. The mean values of the variables and standard deviations are presented in Table 1. The size of the data sample was 231 measurements.

Table 1. Descriptive statistics

\begin{tabular}{|c|c|c|}
\hline Variables & Mean values & $\begin{array}{c}\text { Standard } \\
\text { deviations }\end{array}$ \\
\hline $\boldsymbol{l}_{\mathbf{1}}$ & 799 & 455.6 \\
\hline $\boldsymbol{l}_{\mathbf{2}}$ & 731 & 423.4 \\
\hline $\boldsymbol{a}_{\mathbf{1}}$ & 0.47 & 0.26 \\
\hline $\boldsymbol{a}_{\mathbf{2}}$ & 0.45 & 0.27 \\
\hline $\boldsymbol{I}$ & 1 & 3.17 \\
\hline
\end{tabular}

Figure 4 presents the arrangement of the points for odor strength measurements.
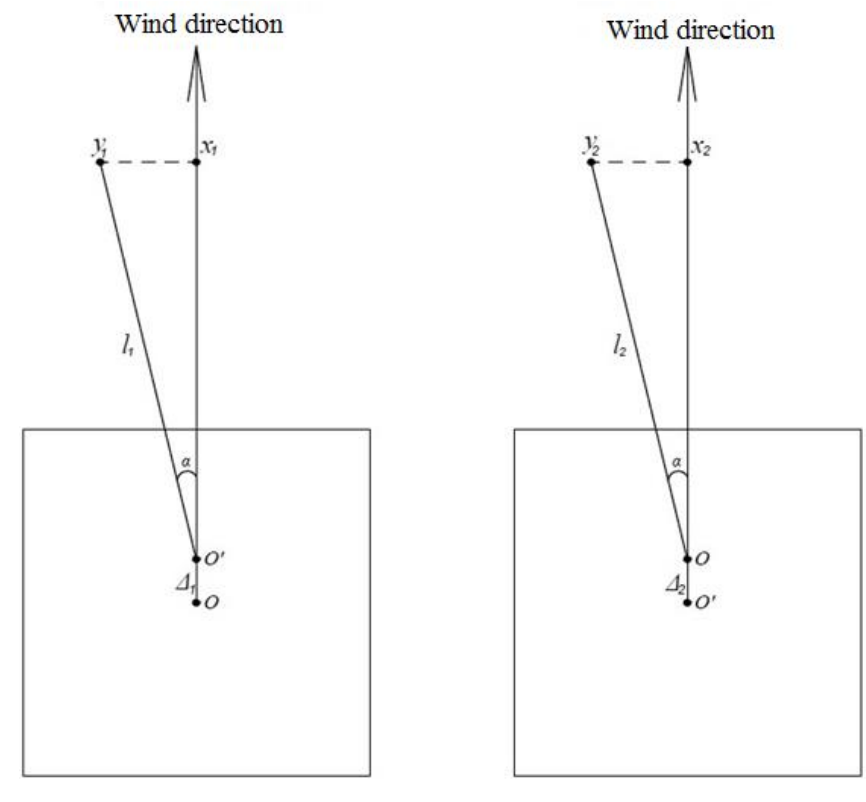

$a$

b

Fig. 4. The arrangement of the points for odor strength measurements. $a$ ) the small odor source; $b$ ) the large odor source 
If we assume that odor dispersion is similar to pollutant dispersion in the atmosphere with jet streams, then odor strength $I$ (estimated by an assessor) can be expressed by the following formula:

$$
I=\frac{1}{\sqrt{2 \pi}}\left(\frac{m_{1}}{\overline{x_{1}}+\Delta_{1}} e^{-k_{1} \frac{y_{1}^{2}}{x_{1}^{2}}}+\frac{m_{2}}{\overline{x_{2}}+\Delta_{2}} e^{-k_{2} \frac{y_{2}^{2}}{x_{2}^{2}}}\right)
$$

where

$$
x_{i}=l_{i} \cos a_{i} ; \quad y_{i}=l_{i} \sin a_{i} ; \quad \overline{x_{i}}=\frac{x_{i}}{D_{i}}-\text { relative coordinate; }
$$

$D_{i}=\sqrt{\frac{4 S_{i}}{\pi}}$ - equivalent diameter of the $i$-th odor source; $D_{1}=4,37 ; D_{2}=43,71$;

$S_{i}$ - area of the $i$-th odor source; $S_{1}=15 \mathrm{~m}^{2} ; S_{2}=1500 \mathrm{~m}^{2}$;

$m_{i}$ - odor strength decrease coefficient;

$k_{i}$ - odor strength dispersion coefficient;

$\Delta_{i}$ - decline of the relative pole $O O_{i}^{\prime}$, where $O_{i}^{\prime}$ - point from which $l_{i}$ and $x_{i}$ are counted; $i=1,2$.

To determine the coefficients in the formula (2) we used the Levenberg-Marquardt algorithm for the Least Squares method, which is more effective and accurate than most general optimization algorithms. The Levenberg-Marquardt algorithm is based on the following methods: Newton's method, the Gauss-Newton algorithm and the method of gradient descent.

For the significance level $\alpha=0.05$ the following results were obtained:

$m_{1}=0,02874 ; \quad m_{2}=7,4124 ; \quad k_{1}=5,356 ; \quad k_{2}=0,6999 ; \quad \Delta_{1}=1,14698 ; \quad \Delta_{2}=-1,3116$.

At the same time, a multiple correlation coefficient $R=0.81$ indicates that there is a high correlation between the response variable $I$ and the explanatory variables $l_{1}, l_{2}, a_{1}, a_{2}$.

Odor strength $I$ is expressed by the following relation:

$$
I=\frac{1}{\sqrt{2 \pi}}\left(\frac{0,02874}{\overline{x_{1}}+1,147} e^{-5,356 \cdot \frac{y_{1}^{2}}{x_{1}^{2}}}+\frac{7,4124}{\overline{x_{2}}-1,3116} e^{-0,7 \cdot \frac{y_{2}^{2}}{x_{2}^{2}}}\right) .
$$

If the model assumes that the shift of the relative poles $\Delta_{i}$ is 0 , i.e. the following relation is searched for:

$$
I=\frac{1}{\sqrt{2 \pi}}\left(\frac{m_{1}}{\overline{x_{1}}} e^{-k_{1} \frac{y_{1}^{2}}{x_{1}^{2}}}+\frac{m_{2}}{\overline{x_{2}}} e^{-k_{2} \frac{y_{2}^{2}}{x_{2}^{2}}}\right),
$$

then with the significance level $\alpha=0.05$ the following results were obtained:

$$
m_{1}=-198,687 ; \quad m_{2}=0,049 ; \quad k_{1}=0,0657 ; \quad k_{2}=0,695 ; \quad \text { multiple }
$$

correlation coefficient $R=0.781$,

In this case, odor strength $I$ is expressed by the relation: 


$$
I=\frac{1}{\sqrt{2 \pi}}\left(\frac{-198,687}{\overline{x_{1}}} e^{-0,0657 \cdot \frac{y_{1}^{2}}{x_{1}^{2}}}+\frac{0,049}{\overline{x_{2}}} e^{-0,695 \cdot \frac{y_{2}^{2}}{x_{2}^{2}}}\right)
$$

\section{Conclusion}

Thus, if there are two emission sources, the above-mentioned relation makes it possible to determine the sanitary protection zone depending on the odor strength and taking into account meteorological conditions (in this case, wind direction).

\section{References}

1. S. Calvert, H.M. Englund, Handbook of Air Pollution Technology, John Wiley and Sons, Inc., 1984.

2. S.V. Svitskov, D.A. Danilovich, V.N. Azarov, Wastewater treatment plants as a malodor source: causes, characteristics and abatement methods, Vodosnabzhenie I sanitarnaya tehnika, 7, 24 - 31 (2016).

3. V.N. Azarov, S.V. Svitskov, T.V. Soloveva, On mathematical model of assessment of odor strength from a wastewater treatment plant in Kalinigrad region, Vestnik Volgoggradskogo gosudarstvennogo arhitekturno-stroitelnogo universiteta. Series: Construction and Architecture, 50 (69), 156-163 (2017).

4. C. M. McGinley, T. D. Mahin, and R. J. Pope, Elements of successful odor/odour laws, WEF Odor/VOC 2000 Specialty Conference. Alexandria, Va.: WEF, 2000.

5. K.C. Hamel, L.W. Walters, C. Sulerud, and M.A. McGinley, Land Application Odor Control Case Study, Proceedings of the Water Environment Federation Residuals and Biosolids Management Conference. 22-25 February 2004, Salt Lake City, UT, Water Environment Federation, Alexandria, VA, 2004.

6. M.A. Lay, C.M. McGinley, A Nasal Chemosensory Performance Test for Odor Inspectors, Water Environment Federation Odors and Air Emissions 2004 Bellevue, WA, 2004.

7. J.G. Nicholls, A. R. Martin, B.G. Wallance, P.A. Fuchs, From Neuron to Brain (LIBROKOM, Moscow, 2017).

8. GN 2.1.6.1338-03. Maximum allowable concentrations of pollutants in ambient air of populated areas.

9. EN 13725:2003. Air Quality - Determination of Odour Concentration by Dynamic Olfactometry.

10. GOST 32673-2014 «Rules of setting regulations and control of malodorous chemicals emissions to the atmosphere».

11. ASTM E 679-04 (Reapproved 2011). Standard Practice for Determination of Odour and Taste Thresholds by a Forced-Choice Ascending Concentration Series Method of Limits.

12. R.C. Brandt, M.A. Adviento-Borbe, H.A. Elliott, E.F. Wheeler, Protocols for Reliable Field Olfactometry Odour Evaluations. Applied Engineering in Agriculture, 27 (3), 457-466. 
13. O.A. Ganzha, T.V. Soloveva, The use of the main components method for describing environmental processes for regulating urban environment quality, Internet-vestnik VolgGASU, Series: Polymathematical, 1 (37) (2015).

14. V.N. Azarov, N.S. Barikaeva, T.V. Solovyeva, Monitoring of fine particulate air pollution as a factor in urban planning decisions, Procedia Engineering, 150, 20012007 (2016).

15. V.N. Azarov, N.V. Menzelintseva, N.Y. Karapuzova, E.O. Fomina, N.A. Pshenichkina, Mathematical model for prognosis of the particulate size distribution in the air of the working areas of cement factories for dust conditions assessment, Vestnik Volgoggradskogo gosudarstvennogo arhitekturno-stroitelnogo universiteta. Series: Construction and Architecture, 44 (63), part 2, 134-144 (2016).

16. V.N. Azarov, S.A. Koshkarev, Environmental safety improvement in the building sector by developing dust removal systems with the use of complex dispersion analysis of dust emissions, Vestnik Volgoggradskogo gosudarstvennogo arhitekturno-stroitelnogo universiteta, Series: Construction and Architecture, 43, 161-174 (2016).

17. V.N. Azarov, T.V. Dontsova, On pollutants balance in the atmosphere of big cities, Internet-vestnik VolgGASU, Series: Polymathematical, 1 (31) (2014).

18. V.N. Azarov, N.V. Menzelitseva, N.Y. Karapuzova, A.M. Redhwan, Main trends of dust conditions normalizing at cement manufacturing plants, International Review of Civil Engineering, 6 (6), 145-150 (2016).

19. V.N. Azarov, M.V. Trokhimchuk, O.P. Sidelnikova, Research of dust concent in the earthworks working area, Procedia Engineering, 150, 2008-2012 (2016).

20. M. Singh, A.K. Pandey, P.K. Singh, G. Singh, R.M. Mishra, Trend of particulate matter in the ambient air of a small city in India, Indian journal of basic and applied research, 1 (4), 70-72 (2016). 